\title{
Using Remote-Sensing Environmental and Fishery Data to Map Potential Yellowfin Tuna Habitats in the Tropical Pacific Ocean
}

\author{
Kuo-Wei Lan ${ }^{1, *}$, Teruhisa Shimada ${ }^{2}$, Ming-An Lee ${ }^{1}$, Nan-Jay Su ${ }^{1}$ and Yi Chang ${ }^{3}$ \\ 1 Department of Environmental Biology Fisheries Science, National Taiwan Ocean University, 2 Pei-Ning Rd., \\ Keelung 20224, Taiwan; malee@mail.ntou.edu.tw (M.-A.L.); nanjay@mail.ntou.edu.tw (N.-J.S.) \\ 2 Graduate School of Science and Technology, Hirosaki University, 1 Bunkyo-cho, Hirosaki-shi 036-8560, \\ Aomori-ken, Japan; shimadat@hirosaki-u.ac.jp \\ 3 Institute of Ocean Technology and Marine A ffairs, National Cheng Kung University, No. 1, \\ University Road, Tainan City 701, Taiwan; yichang@mail.ncku.edu.tw \\ * Correspondence: kwlan@mail.ntou.edu.tw; Tel.: +886-2-4622192 (ext. 5027)
}

Academic Editors: Chung-Ru Ho, Xiaofeng Li and Prasad S. Thenkabail

Received: 3 January 2017; Accepted: 1 May 2017; Published: 5 May 2017

\begin{abstract}
Changes in marine environments affect fishery resources at different spatial and temporal scales in marine ecosystems. Predictions from species distribution models are available to parameterize the environmental characteristics that influence the biology, range, and habitats of the species of interest. This study used generalized additive models (GAMs) fitted to two spatiotemporal fishery data sources, namely $1^{\circ}$ spatial grid and observer record longline fishery data from 2006 to 2010, to investigate the relationship between catch rates of yellowfin tuna and oceanographic conditions by using multispectral satellite images and to develop a habitat preference model. The results revealed that the cumulative deviances obtained using the selected GAMs were $33.6 \%$ and $16.5 \%$ in the $1{ }^{\circ}$ spatial grid and observer record data, respectively. The environmental factors in the study were significant in the selected GAMs, and sea surface temperature explained the highest deviance. The results suggest that areas with a higher sea surface temperature, a sea surface height anomaly of approximately -10.0 to $20 \mathrm{~cm}$, and a chlorophyll-a concentration of approximately $0.05-0.25 \mathrm{mg} / \mathrm{m}^{3}$ yield higher catch rates of yellowfin tuna. The $1^{\circ}$ spatial grid data had higher cumulative deviances, and the predicted relative catch rates also exhibited a high correlation with observed catch rates. However, the maps of observer record data showed the high-quality spatial resolutions of the predicted relative catch rates in the close-view maps. Thus, these results suggest that models of catch rates of the $1^{\circ}$ spatial grid data that incorporate relevant environmental variables can be used to infer possible responses in the distribution of highly migratory species, and the observer record data can be used to detect subtle changes in the target fishing grounds.
\end{abstract}

Keywords: tropical Pacific Ocean; yellowfin tuna; generalized additive models; habitat preference

\section{Introduction}

The biophysical environment plays an essential role in controlling the distribution and abundance of top predators, such as tuna, in the ocean. However, the integrity of large marine ecosystems has been compromised because of the depletion of the ocean's top predators by large-scale fishing operations [1,2]. Since the 1950s, large-scale fisheries have targeted tuna, billfish, and other large predators in the ecosystem of the tropical Pacific Ocean (TPO) [3]. Comparison of the catch, size, and species composition of research surveys of the 1950s and 1990s suggests a substantial decline in the abundance and mean size of these large predators and an increased abundance of formerly rare 
species [3-5]. Changes in marine environments also affect fishery resources at different spatial and temporal scales [6,7]. Therefore, the availability of oceanographic and biological information concerning large predators will improve fishing operations as well as the management of fishery resources [8-10].

Yellowfin tuna (Thunnus albacares) are a vital component of tuna fisheries throughout the TPO and are harvested using a wide variety of gear types, including small-scale artisanal fisheries in the Pacific islands and distant-water large longliners and purse seiners that operate in equatorial and tropical waters [11]. In the northeastern Pacific Ocean, archival tag data of the mature yellowfin tuna show cyclical movements between suitable spawning and feeding ground habitats, and most yellowfin tuna remain at shallow depths $(<50 \mathrm{~m})$ at night and do not dive into greater depths $(>100 \mathrm{~m})$ during the day $[1,12]$. Remote satellite observations of the sea surfaces provide considerable information for assessing and improving the potential yield of fishing grounds. The sea surface temperature (SST) and chlorophyll (Chl)-a concentration have been suggested to play a role in generating distribution patterns and variability in tuna abundance [12-15]. Studies have indicated that yellowfin tuna prefer warm waters and are found in regions with a high Chl-a concentration and net primary productivity [1,12-15]. The sea surface height can be used to infer oceanic features, such as current dynamics and fronts [16], and the mesoscale oceanic dynamical processes including eddies, convergences and upwelling can be reflected in sea surface height anomaly (SSHA). Pelagic tuna species aggregate around the fronts and eddies where their preferred prey gathers $[9,17]$.

As such, resolving the potential effects of environmental variability on species habitats requires high-resolution spatiotemporal oceanographic and fishery data $[18,19]$. Large-scale longline fisheries in Taiwan are the major producers of tuna in the western and central TPO since the 1950s, and yellowfin tuna is a vital target species [20]. In the TPO, historical catch information and logbook data for Taiwanese longline fishery has been available since 1964. Previous studies have investigated the stock assessment and fishery oceanography for high trophic level predators, including bigeye tuna, yellowfin tuna, albacore, and billfish, and mostly used Taiwanese longline fishery data with $5^{\circ}$ grid spatial resolution $[15,17,20,21]$. However, averaging the environmental data (i.e., SST, Chl-a, and SSH) over a $5^{\circ}$ block would lose detail information for the small scale environmental variabilities, such as the fluctuation of eddy current and continuous change of SSTs. Consequently, the finer spatial resolution (e.g., $1^{\circ}$ grid spatial resolution and observer record fishing position data) is essential for fisheries environmental studies and should be adopted to detect the distribution patterns of high trophic level predators for small-scale areas.

Catch rate models that incorporate relevant variables associated with environmental variations can be used to infer possible factors influencing the distribution of highly migratory species, such as yellowfin tuna. The distribution and abundance of tuna are environment sensitive and strongly associate with high-density foraging $[9,22,23]$. Yellowfin tuna most likely respond synoptically to certain environmental factors. Thus, combining several environmental factors that might provide novel insight into detecting high-density tuna foraging areas and thus potential fishing grounds (tuna habitats) is essential. Generalized additive models (GAMs) are a semiparametric extension of generalized linear models with an assumption that the functions are additive and the components are smooth [24]. The strength of GAMs is their ability to handle highly nonlinear and nonmonotonic relationships between responses and the set of explanatory variables, making them ideal for expressing underlying relationships in ecological systems [25]. This technique has been successfully used to describe the habitat preferences of target and nontarget species and has often been used to predict species distributions $[7,9,21,25]$.

This study investigated the relationship between catch rates of yellowfin tuna and oceanographic conditions (SST, Chl-a, and SSH) by using multispectral and microwave radar satellite images and developed a habitat preference model by using GAMs in the TPO. Two sources of spatiotemporal fishery data, namely a $1^{\circ}$ spatial grid compiled from logbooks and observer record data (O-data) reported by the fishing fleet observers of the Taiwanese longline fishery industry, were used in this study. The O-data were apparently daily catch, detailed fishing position, and effort data from individual fishing fleet. 
To investigate the relationship of habitat modelling by applying the GAMs at different resolution scales can improve our knowledge of the deviance explained and predicted accuracy of yellowfin tuna in the Pacific Ocean. Understanding the effects of environmental conditions on fish catch rates through fishing condition and habitat preference model studies is an essential step for the ecosystem-based management of fisheries, which is increasingly becoming a standard approach in management policy.

\section{Data and Methods}

\subsection{Yellowfin Tuna Fishery Data}

Two spatiotemporal fishery data sources used for analyses from 2006 to 2010 were provided by the Overseas Fisheries Development Council of Taiwan. The fishery data of the $1^{\circ}$ spatial grid and O-data comprised daily fishing positions (latitude and longitude), fishing effort (number of hooks), fishing date, and catch (in number). The observed catch rate was calculated as the number of fish captured per 1000 hooks (fish $/ 10^{3}$ hooks). The catch and effort data were aggregated into 7- and 15-day resolved datasets to match the temporal scales of environmental data.

\subsection{Remotely Sensed Environmental Data}

Satellite-derived SST data were used to produce daily high-resolution optimally interpolated SST and downloaded from the National Climatic Data Center (https://www.ncdc.noaa.gov/). The in situ SST data were blended with those from the Advanced Very High Resolution Radiometer (AVHRR) infrared satellite and Advanced Microwave Scanning Radiometer for the Earth Observing System (AMSR-E). The analyses have a spatial grid resolution of $0.25^{\circ}$ and a temporal resolution of one day. The NASA Aqua satellite contains the Moderate Resolution Imaging Spectroradiometer sensor (MODIS) that is used for detecting the Chl-a concentration in oceans worldwide, and its data was downloaded from the NASA Ocean Color Web (http:/ /oceancolor.gsfc.nasa.gov/). The level 3 standard mapped image of MODIS Chl-a dataset has a daily temporal resolution and spatial resolution of $4.6 \mathrm{~km}$ (at the equator). The sea surface height anomaly (SSHA) was obtained from the Archiving, Validation, and Interpretation of Satellite Oceanographic data. A combined SSHA data product from the TOPEX Poseidon, ERS, and Jason 1 satellite with approximately $1 / 3^{\circ}$ spacing resolution is used. The SSHA is calculated with respect to the seven-year mean (January 1993 to December 1999) and mapped onto a global irregular grid with approximately $1 / 3^{\circ}$ spacing.

7- and 15-day averaged composite maps were constructed from the daily Chl-a maps to reduce missing data due to cloud coverage. The areal coverage of 7- and 15-day averaged maps were approximately $57.75 \%$ and $77.5 \%$, respectively. The 15 -day temporal resolution to determine latitude and longitude positions from fishery data to match environmental data (SST, Chl-a, and SSHA) and to fit GAMs.

\subsection{Statistical Models for Spatial Predictions of Catch Rate}

GAMs were used to predict the spatial patterns of potential yellowfin tuna habitats from the relationships determined between environmental variations and catch rates in 2006-2009. The GAMs were constructed using R (Version 2.15.0) by using the GAM function of the mgcv package [26], with the catch rate as the response variable and environmental factors (SST, Chl-a, and SSHA) as predictor variables. GAMs facilitate analyzing multiple nonlinear relationships between covariates and response variables in a semiparametric manner and explain the variance in the response variable [24].

The GAM was construed as follows:

$$
\log (\text { catch rate }+c)=a 0+s\left(x_{1}\right)+s\left(x_{2}\right)+s\left(x_{3}\right)+\ldots s\left(x_{n}\right)
$$

All covariates were considered to be continuous, and the effective degrees of freedom were estimated for each main factor. In Equation (1), $a 0$ is the model constant and $s\left(x_{n}\right)$ is a spline smoothing function for each model covariate $x_{n} . c$ is $10 \%$ of the overall mean of the observed catch rate. Because the log-link function cannot handle zeroes, a constant value of $\mathrm{c}$ was added to all catch rates. A constant 
value of $\mathrm{c}$ is commonly used in catch rate standardizations. The model with the optimal conformation was selected using a stepwise procedure that was based on the lowest Akaike's Information Criterion. Diagnostic plots (i.e., the distribution of residuals and quantile-quantile plots) were used to evaluate the model conformation.

The selected GAMs were used to predict the relative abundance of yellowfin tuna across the TPO from 2006 to 2009. Furthermore, the selected GAMs that were based on data from 2006-2009 and the environmental data of 2010 were used to predict the relative abundance of yellowfin tuna in the 2010. The predicted catch rates were mapped using IDL 8.0 and subsequently overlaid with the observed catch rates. We further compared the observed and predicted catch rates of two sources of spatiotemporal fishery data by linear regression.

\section{Results}

\subsection{Catch Rate Patterns of Yellowfin Tuna in the TPO}

The spatial distribution of the observed catch rates from 2006 to 2009 of the $1^{\circ}$ spatial grid data (Figure 1) showed seasonal variations. The highest observed catch rates $\left(>2.28\right.$ inds $/ 10^{3}$ hooks) were mainly concentrated in the TPO, particularly in the range of $0^{\circ}-20^{\circ} \mathrm{S}$ and $150^{\circ} \mathrm{E}-160^{\circ} \mathrm{W}$ and extended to $160^{\circ} \mathrm{W}$ in the second quarter. Moreover, the spatial distribution of O-data (Figure 2) also indicated that the highest observed catch rates ( $>2.96$ inds $/ 10^{3}$ hooks) were mainly concentrated in the TPO. However, the O-data covered only few vessels operating in the TPO, and seasonal variations were not obvious because of the lack of data.

\subsection{GAM Analysis and Selection of Error Model and Explanatory Variables}

The total number of 15-day averaged observations used in the GAMs was 18,657 for the $1^{\circ}$ spatial grid data and 2554 for the O-data in 2006-2009. The model selection processes are shown in Table 1 , and the variables used were statistically significant $(p<0.01)$ for SSHA, SST, and Chl-a. The addition of predictor variables at different levels resulted in an increase in the deviance explained. In the one variable models, SST explained the highest deviance $\left(32.3 \%\right.$ for $1^{\circ}$ spatial grid data and $11.0 \%$ for O-data) and SSHA explained the lowest deviance $\left(0.16 \%\right.$ for $1^{\circ}$ spatial grid data and $1.46 \%$ for O-data). The cumulative deviances explained by the selected GAMs (lowest AIC value and highest deviance) were $33.6 \%$ and $16.5 \%$ in the $1^{\circ}$ spatial grid data and O-data, respectively. Normal quantile-quantile plots indicated that the distributions of residuals for the selected GAMs of the two sources of spatiotemporal fishery data adequately conformed to the assumption of a Gaussian distribution (Figures $3 a$ and $4 a$ ).

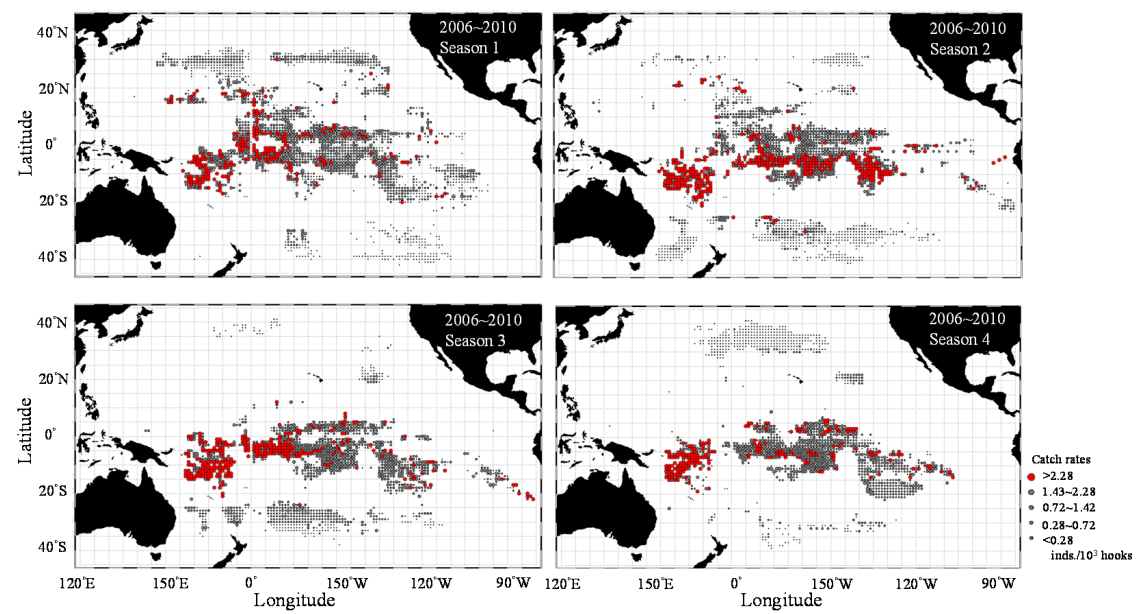

Figure 1. Spatial seasonal distributions of $1^{\circ}$ spatial grid-averaged observed catch rates of yellowfin tuna for the entire study period from 2006 to 2010. 


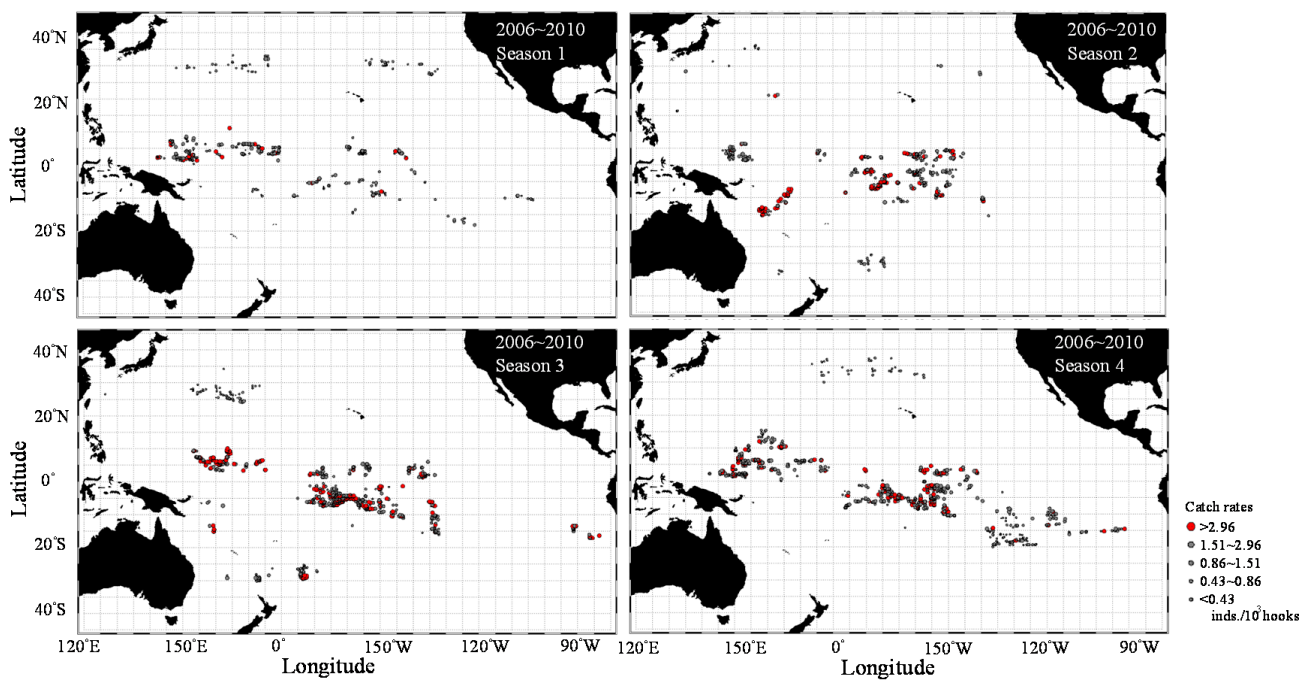

Figure 2. Spatial seasonal distributions of observer record data averaged observed catch rates of yellowfin tuna for the entire study period from 2006 to 2010.

Table 1. Deviance explained, and AIC of yellowfin tuna catch rates values explained in a generalized additive model (GAM) with sequentially added variables. (a) $1^{\circ}$ spatial grid data (b) observer record data from 2006 to 2009 in the tropical Pacific Ocean (TPO).

\begin{tabular}{|c|c|c|c|}
\hline \multicolumn{4}{|l|}{ (a) } \\
\hline & Deviance Explained & AIC & $p$ Value \\
\hline (SST) & $32.30 \%$ & $54,340.69$ & $<0.01$ \\
\hline (CHL) & $6.20 \%$ & $60,466.75$ & $<0.01$ \\
\hline (SSHA) & $0.16 \%$ & $61,644.42$ & $<0.01$ \\
\hline$(\mathrm{SST})+(\mathrm{CHL})$ & $33.50 \%$ & $54,023.75$ & $<0.01$ \\
\hline$(\mathrm{SST})+(\mathrm{SSHA})$ & $32.40 \%$ & $54,332.00$ & $<0.01$ \\
\hline$(\mathrm{CHL})+(\mathrm{SSHA})$ & $5.65 \%$ & 6058.38 & $<0.01$ \\
\hline$(\mathrm{SST})+(\mathrm{CHL})+(\mathrm{SSHA})$ & $33.60 \%$ & $54,003.60$ & $<0.01$ \\
\hline \multicolumn{4}{|l|}{ (b) } \\
\hline & Deviance Explained & AIC & $p$ Value \\
\hline (SST) & $11.00 \%$ & 5924.31 & $<0.01$ \\
\hline (CHL) & $2.65 \%$ & 6150.07 & $<0.01$ \\
\hline (SSHA) & $1.46 \%$ & 6175.01 & $<0.01$ \\
\hline$(\mathrm{SST})+(\mathrm{CHL})$ & $14.60 \%$ & 5843.11 & $<0.01$ \\
\hline$(\mathrm{SST})+(\mathrm{SSHA})$ & $13.10 \%$ & 5873.93 & $<0.01$ \\
\hline$(\mathrm{CHL})+(\mathrm{SSHA})$ & $3.75 \%$ & 6131.81 & $<0.01$ \\
\hline$(\mathrm{SST})+(\mathrm{CHL})+(\mathrm{SSHA})$ & $16.50 \%$ & 5796.74 & $<0.01$ \\
\hline
\end{tabular}

For the $1^{\circ}$ spatial grid data, a positive association was observed between the catch rates and SST of approximately $25.0^{\circ} \mathrm{C}-30.0^{\circ} \mathrm{C}$ (Figure 3b), an SSHA of approximately -10.0 to $20.0 \mathrm{~cm}$ (Figure 3c), and a Chl-a concentration of approximately $0.05-0.25 \mathrm{mg} / \mathrm{m}^{3}$ (Figure $3 \mathrm{~d}$ ). The association between the catch rates of $\mathrm{O}$-data and environmental factors were obvious the similar trends for the $1^{\circ}$ spatial grid data (Figure $4 b-d)$. 

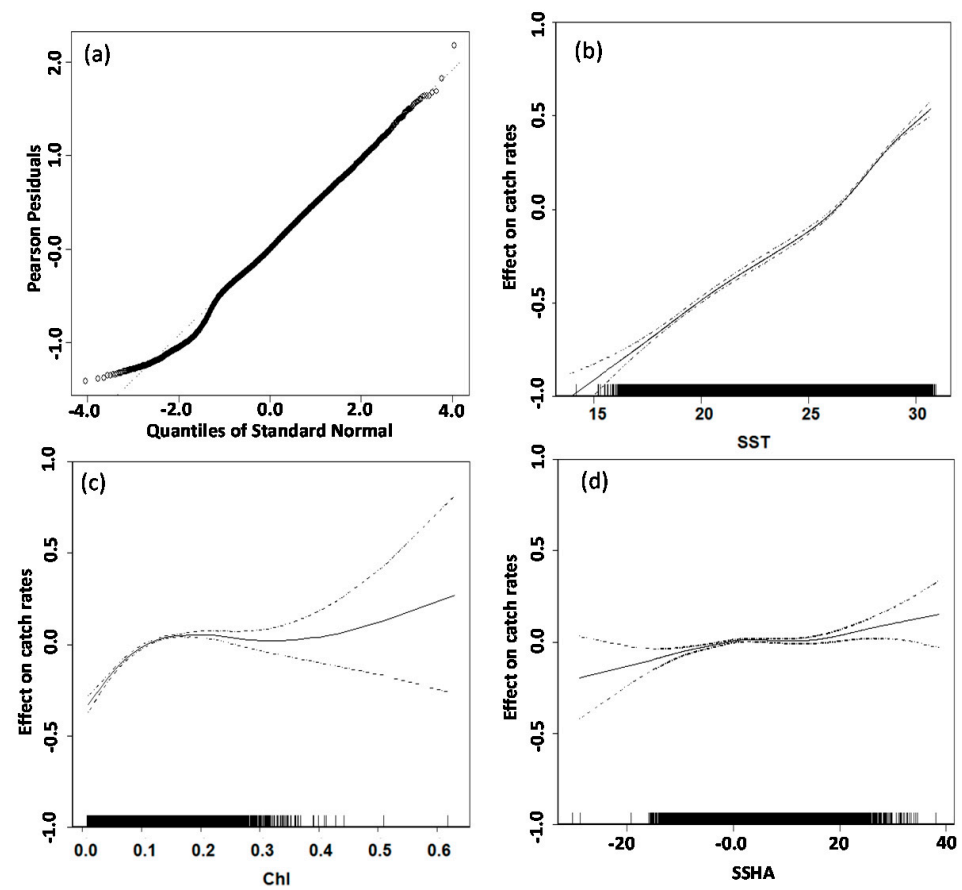

Figure 3. (a) Normal quantile-quantile plots (b) Sea surface temperature (SST), (c) chlorophyll (Chl)-a, and (d) sea surface height anomaly (SSHA) on $1^{\circ}$ spatial grid catch rates of yellowfin tuna in the TPO. The solid and black-dotted lines show the fitted GAM function and 95\% confidence intervals, respectively. The relative density of data points is indicated by the rug plot on the $\mathrm{x}$-axis, and the $\mathrm{y}$-axis shows the results of smoothing the fitted values. Values of predictor variable showing a positive effect on catch rates were read as all values for which the fitted GAM function was above the zero axis.
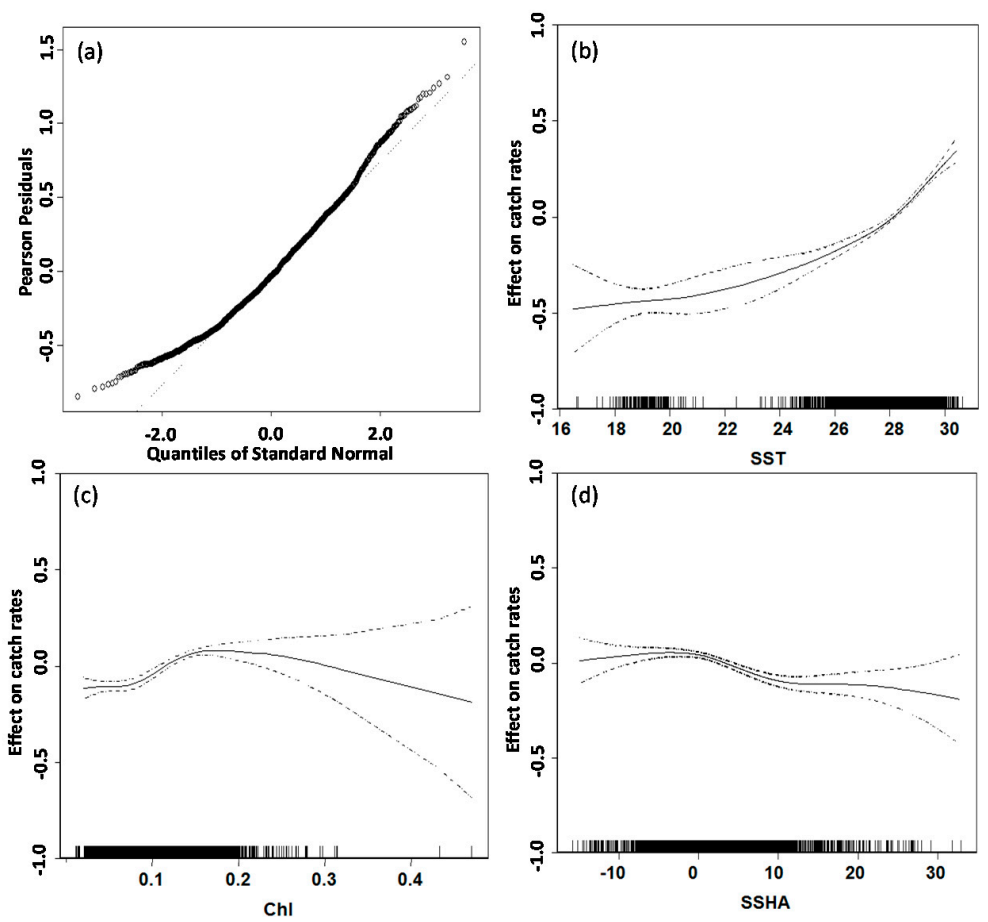

Figure 4. (a) Normal quantile-quantile plots (b) Sea surface temperature (SST), (c) chlorophyll (Chl)-a, and (d) sea surface height anomaly (SSHA) on observer record data catch rates of yellowfin tuna in the tropical Pacific Ocean. See Figure 3 for legends. 


\subsection{Predicted Spatial Distribution of Yellowfin Tuna in the TPO}

All the observed catch rates were plotted on the model-predicted relative abundance maps to examine the validation of the model predictions (Figures 5 and 6). The predicted relative catch rates exhibited trends similar to those of the observed catch rates and had a significantly high correlation with the $1^{\circ}$ spatial grid data $(p<0.05, r=0.58)$ and O-data $(p<0.05, r=0.38)$.

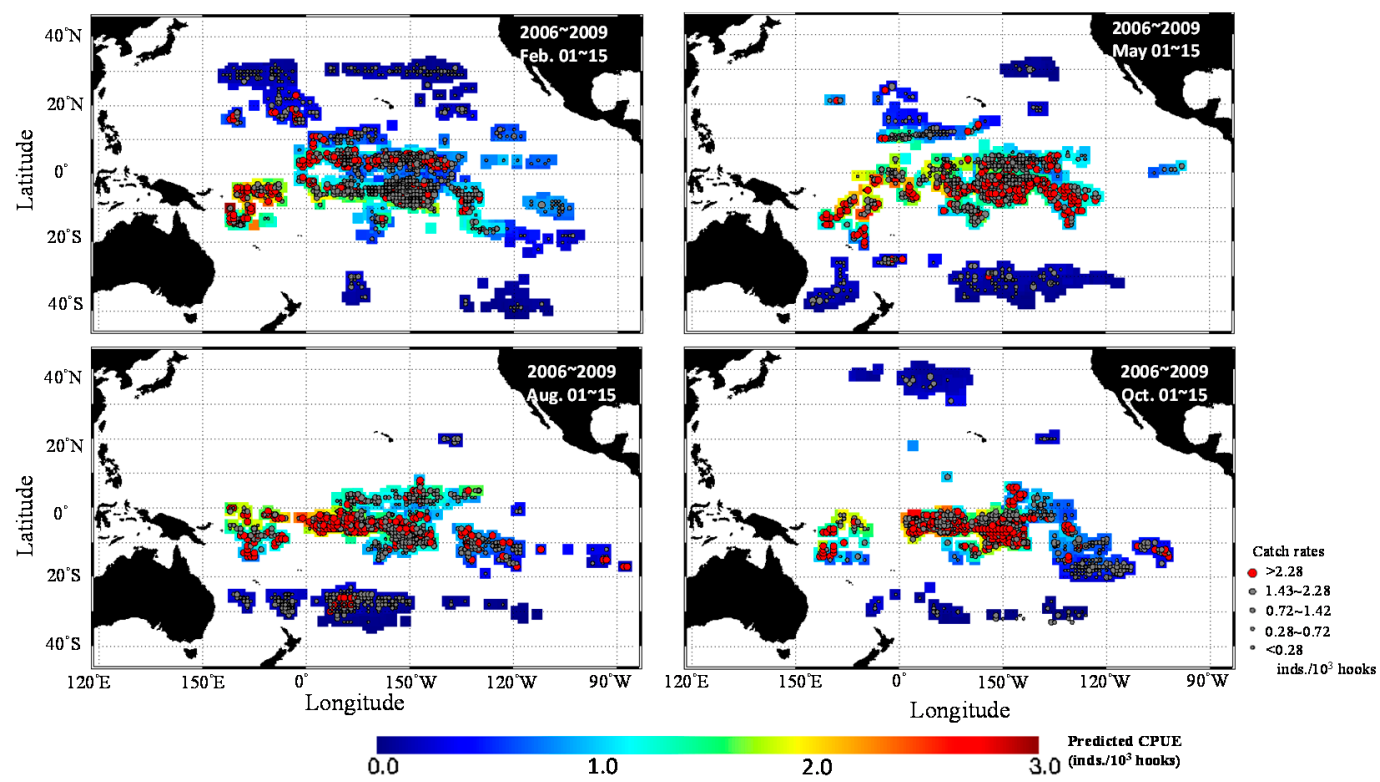

Figure 5. Distribution images of 15-day averaged observed catch rates (solid circles) overlaid on the predicted catch rates of the $1^{\circ}$ spatial grid fishery data for February, May, July, and October in the TPO.
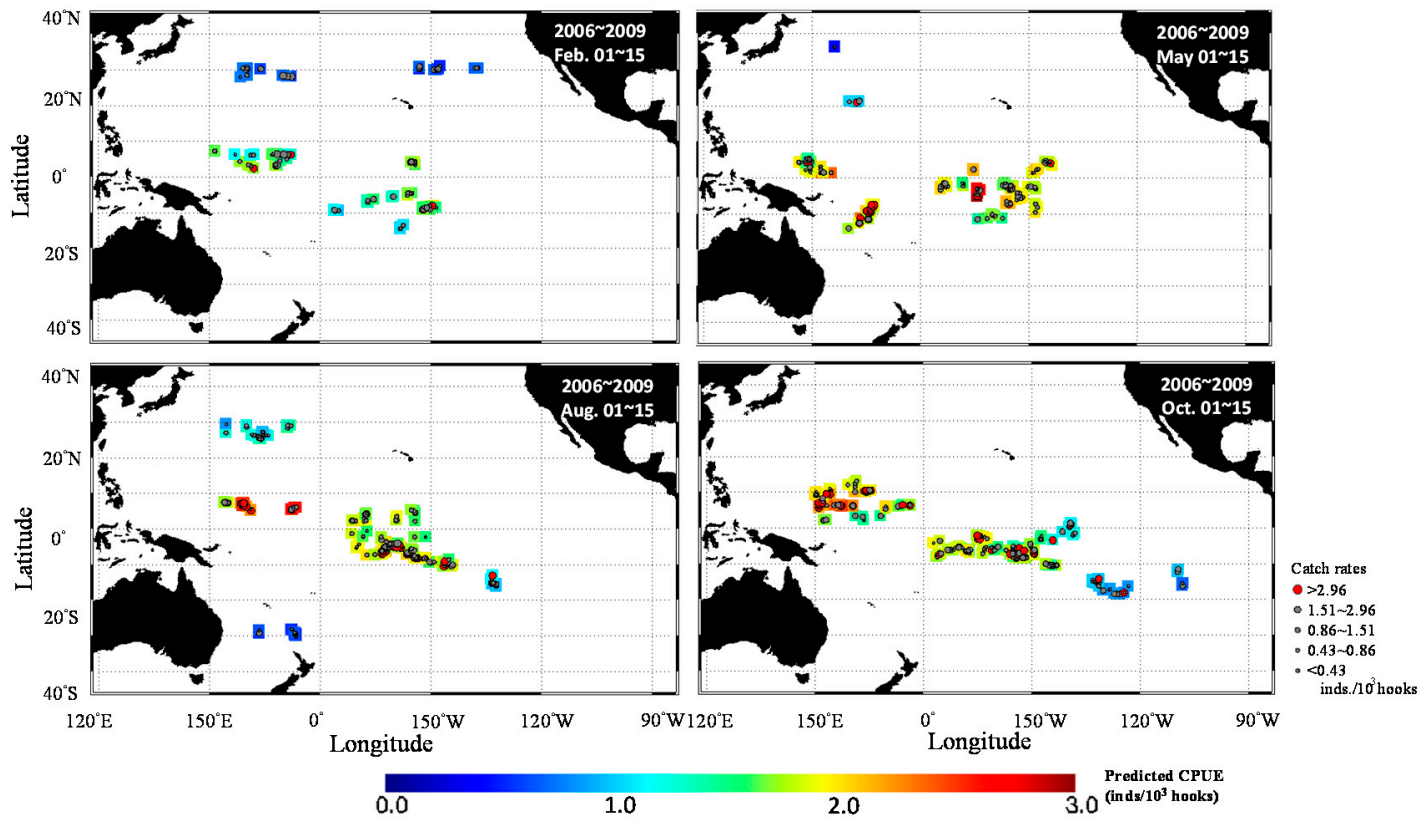

Figure 6. Distribution images of 15-day averaged observed catch rates (solid circles) overlaid on the predicted catch rates of observer record data for February, May, July, and October in the TPO.

Furthermore, the model-predicted relative abundance in the TPO for each quarter during 2006-2009 of the $1^{\circ}$ spatial grid and O-data is shown in Figures 7 and 8 (2009 as an example). A high relative abundance was observed in the western areas in the first quarter (Figure 7a) and extended 
to the central and eastern areas after the second quarters (Figure $7 \mathrm{~b}-\mathrm{d}$ ). The relative abundance of the $\mathrm{O}$-data was lower than of the $1^{\circ}$ spatial grid data but showed the similar patterns (Figure 8). The high catch rates of $\mathrm{O}$-data were mainly concentrated in the western $\left(150^{\circ} \mathrm{E}-170^{\circ} \mathrm{E}\right)$ and central $\left(150^{\circ} \mathrm{W}-170^{\circ} \mathrm{W}\right)$ region in the TPO.
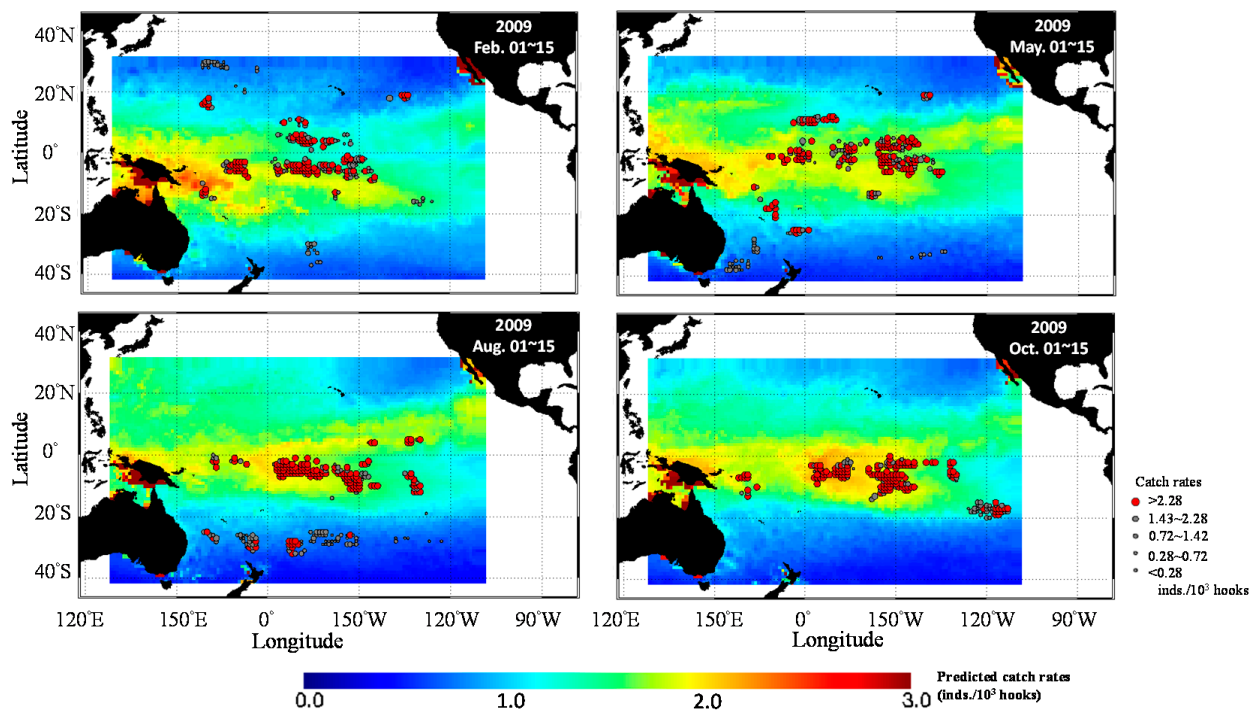

Figure 7. Distribution images of 15 -day averaged $1^{\circ}$ spatial grid-observed catch rates (solid circles) overlaid on the predicted catch rates of yellowfin tuna $\left(1.0^{\circ}\right.$ pixel) for the TPO on February, May, July, and October 2009.
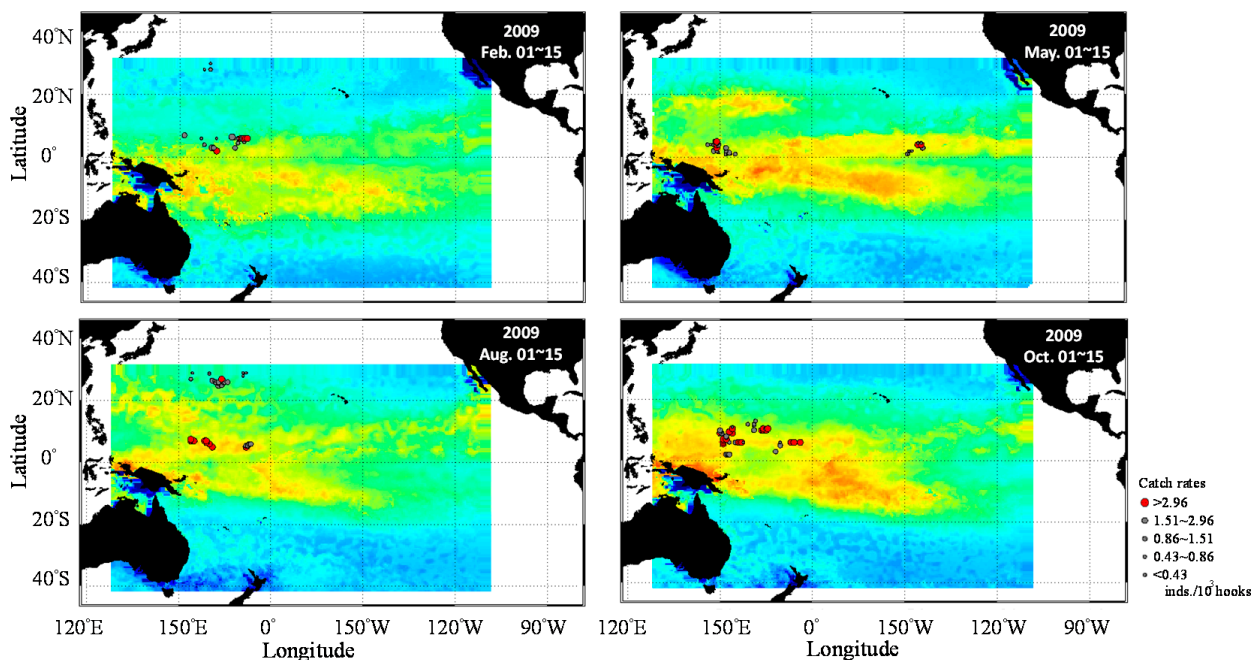

0.0

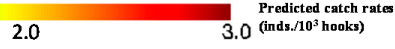

Figure 8. Distribution images of 15-day averaged observer record-observed catch rates (solid circles) overlaid on the predicted catch rates of yellowfin tuna $\left(0.25^{\circ}\right.$ pixel $)$ for the TPO for February, May, July, and October 2009.

The closed-view maps of the two fishery data sources for the area in the red box with a higher relative abundance in Figure 9a,c are shown in Figure 9b,c, respectively. The close-view maps of the $1^{\circ}$ spatial grid show that the higher relative abundances were concentrated in the central TPO (Figure 9a) and the $\mathrm{O}-$ data was concentrated in the range of $160^{\circ} \mathrm{W}-176^{\circ} \mathrm{W}$ and $4^{\circ} \mathrm{S}-8^{\circ} \mathrm{S}$ (Figure $9 \mathrm{~b}$ ). The high observed catch rates of the $1^{\circ}$ spatial grid were corresponded to the high relative abundance (Figure $9 \mathrm{~b}$ ) and the O-data maps showed the high-quality spatial resolutions (Figure 9d). 
(a)

(b)
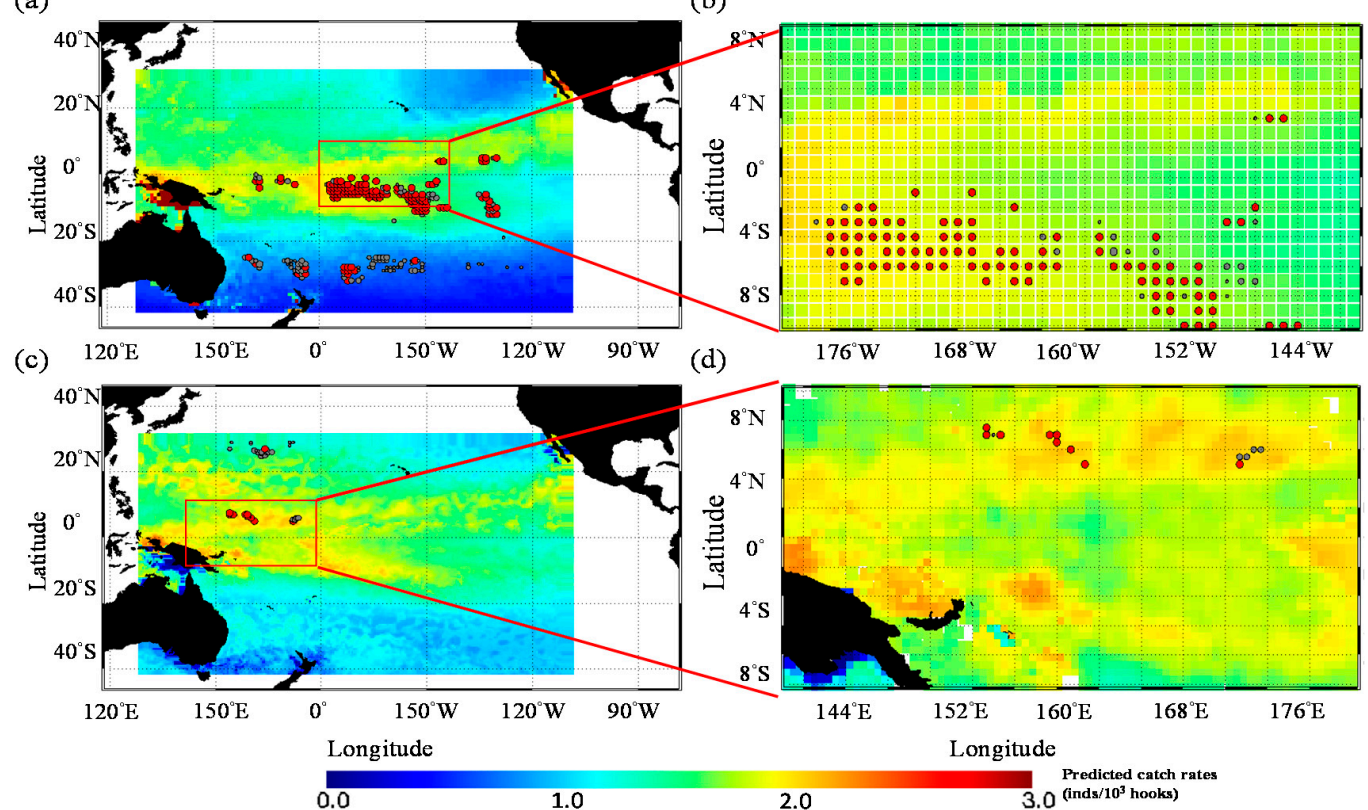

Figure 9. Distribution images of 15-day averaged observer catch rates (solid circles) overlaid on the predicted catch rates of yellowfin tuna (a) $1^{\circ}$ spatial grid and (b) observer record data for 1-15 August 2009, in the TPO. (c) and (d) are the close-view images for the area in the red box (a) and (b), respectively.

On the basis of the aforementioned results, the cumulative deviances of selected GAMs and correlations between observed and predicted relative abundance were higher for the $1^{\circ}$ spatial grid data. In the $1^{\circ}$ spatial grid, the relative abundance of yellowfin tuna in 2010, predicted by the selected GAMs (2006-2009) and environmental data of 2010, was similar to the observed catch rates in 2010 (Figure 10). The predicted and observer catch rates exhibited a significant correlation throughout the year $(p<0.05)$, and the highest and lowest correlations were observed in November and April, respectively (Figure 11).
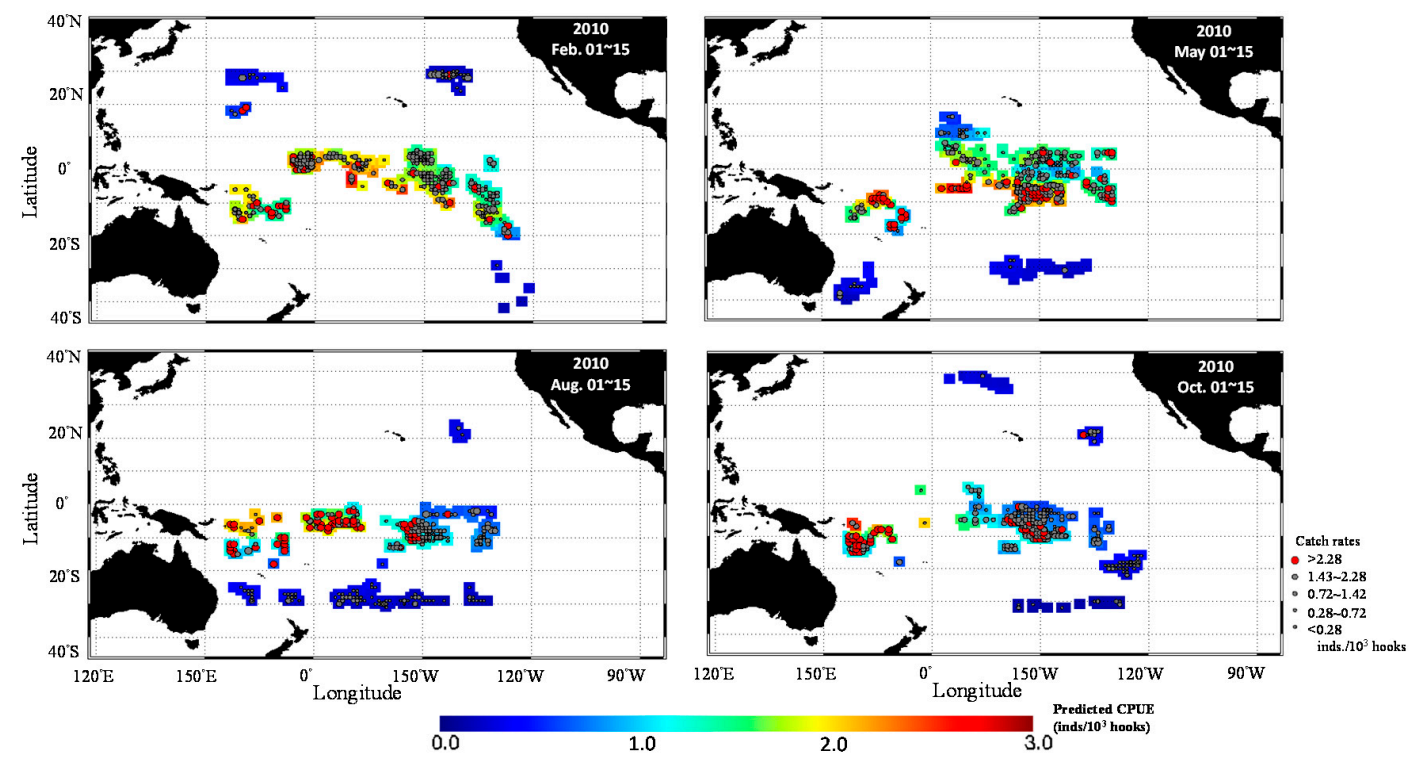

Figure 10. Distribution images of 15 -day averaged $1^{\circ}$ spatial grid-observed catch rates (solid circles) overlaid on the predicted catch rates of yellowfin tuna for February, May, July, and October 2010, in the TPO on the basis of the GAM model from 2006 to 2009. 


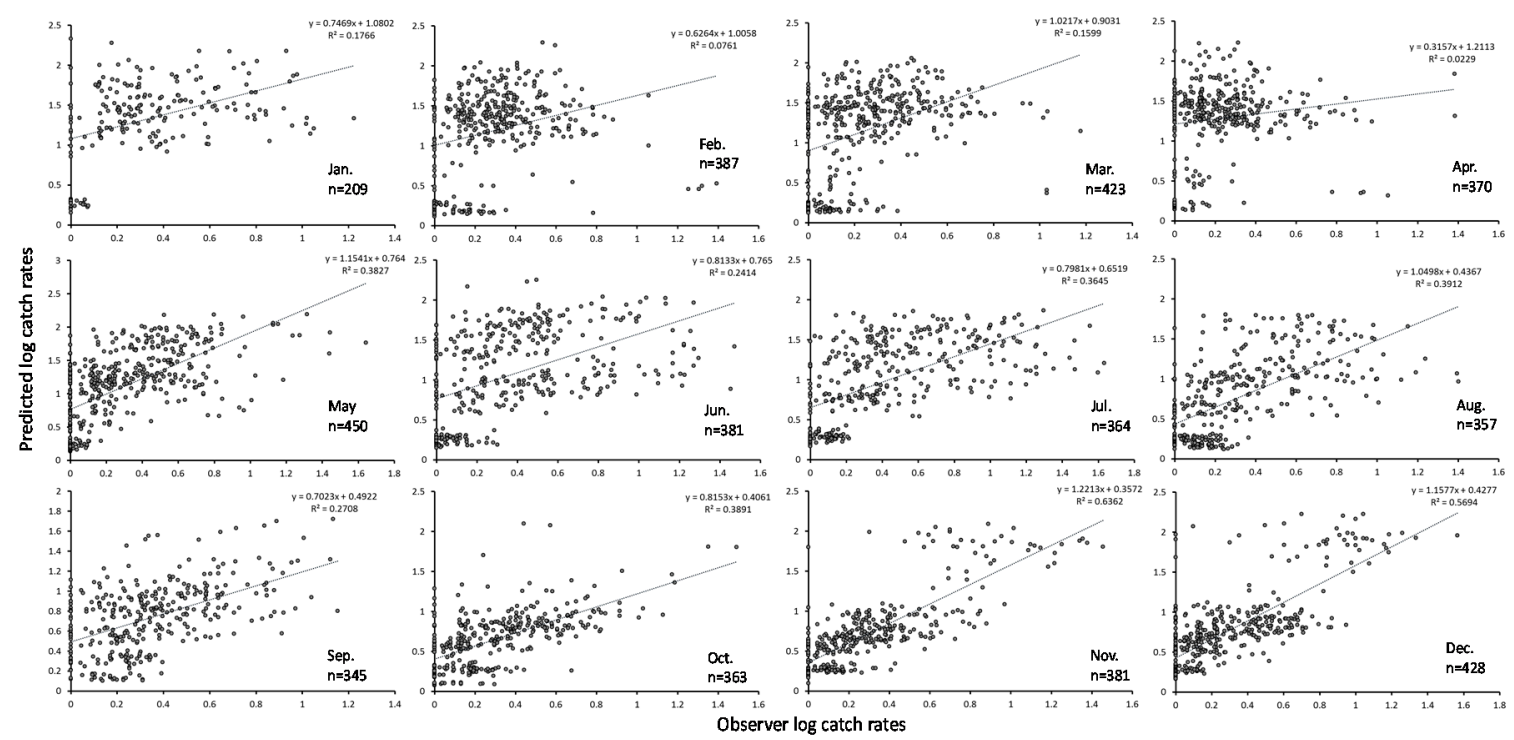

Figure 11. Relationship between the observed catch rates and predicted catch rates of yellowfin tuna obtained from the $1^{\circ}$ logbook data in 2010 on the basis of the GAM model from 2006 to 2009.

\section{Discussion}

Predictions using species distribution models are most effective when sufficient location data, free from sampling bias, are available to parameterize the environmental characteristics that influence the biology, range, and habitats of the species of interest [27]. The different spatiotemporal fishery-dependent datasets may have a sampling bias introduced by behavioral effects related to fishing operations, accuracy correction, and government restrictions. However, these data are the most abundant and widely available for fisheries scientists and managers $[7,13]$. The present findings reveal that the environmental factors account for a considerable proportion of catch rate variations of yellowfin tuna in the TPO from the two sources of spatiotemporal fisheries data. The effects of environmental variables on yellowfin tuna distributions and fisheries that utilize the stock could be evaluated because the statistical model included relevant environmental variables.

The relative abundance of yellowfin tuna in the TPO changed seasonally and between years because of interannual variability in ocean conditions and behaviors of yellowfin tuna. The environmental factors of SST, Chl-a, and SSHA in the study were significant in the selected GAMs and indicated that the major fishing seasons were in the second and third quarters and were concentrated in western and central TPO. These results suggest that the areas with a higher SST, an SSHA of approximately $10.0-20 \mathrm{~cm}$, and Chl-a concentration of approximately $0.05-0.25 \mathrm{mg} / \mathrm{m}^{3}$ yield higher catch rates of yellowfin tuna. The SST is a vital variable for more comprehensively understanding the interactions between ocean and atmosphere related to fish behaviors $[14,17,28]$. Typically, average SSTs are higher in the western Pacific than in the eastern Pacific, and annual maximum temperatures of approximately $30{ }^{\circ} \mathrm{C}$ characterize the western Pacific warm pool. The SST varies seasonally and varies up to $7{ }^{\circ} \mathrm{C}$ throughout the year away from the equator, and the interannual variability is mainly associated with the climatic variability $[23,29]$. Yellowfin tuna primarily occur in waters where surface temperatures are $20^{\circ} \mathrm{C}-30^{\circ} \mathrm{C}$, although their low numbers have been reported to occur in waters having a temperature of $15{ }^{\circ} \mathrm{C}[1,12-15]$. Temperature appears to influence the distribution of yellowfin tuna in all regions, except for the eastern Pacific Ocean where both temperature and oxygen concentrations contribute to a cold hypoxic environment, restricting the distribution of most tuna and billfish [30].

Furthermore, high catch rates mostly did not occur in areas with the highest Chl-a concentrations but more so in areas with intermediate Chl-a concentrations. The phenomenon suggests that productivity per se does not cause tuna aggregation; however, the downstream development of secondary production provides an attractive habitat for yellowfin tuna and other tuna [23]. Therefore, 
Lan et al. [15] and Yen and $\mathrm{Lu}$ [31] have reported a positive relationship between high tuna abundance in high pigment concentrations and appeared time-lagged correlation in the Arabian Sea and tropical Pacific, respectively. The short temporal response of yellowfin tuna catches to seasonal changes also suggests that shifts in the distribution of the longline fleet are more strongly influenced by changing of sea temperature rather than Chl-a concentration [9,32].

The SSHA used in the study was obtained from a combined mulitsatellite data product. Admittedly, at least two altimetric missions are needed to resolve the main space and time scales of ocean circulation and allow a mapping of the sea level and ocean circulation variations with a suitable accuracy, particularly of the mesoscale phenomena [33-35]. The high-resolution merged multi-SSHA maps reduce missing data and mapping errors than do either individual datasets and more realistic sea levels and geostrophic velocity statistics [35]. Nieto et al. [10] proposed that predators (i.e., pelagic tuna species) aggregate around the fronts and eddies where their preferred prey gathers. The mesoscale oceanographic features would lead to the aggregation of tuna forage both by entrainment and by encouraging vertical mixing and introducing nutrients into the photic zone, thus promoting phytoplankton growth, which may subsequently attract predators from higher trophic levels [36,37]. These results indicate that the catch rate of yellowfin tuna was positively correlated with SSHA values of approximately -10.0 to $20.0 \mathrm{~cm}$ and implied a preference for areas with zero anomalies and closely associated with edges of warm and cool eddies.

The $1^{\circ}$ spatial grid data collected from the logbooks of all Taiwanese distant-water tuna longline fisheries operating in the TPO were crosschecked with the daily report to verify the set location [38]. Subsequently, the daily catch and effort by $5^{\circ}$ and $1^{\circ}$ square blocks were computed by summing the catches and effort with similar fishing times and areas. The O-data recorded by the fishing fleet observers were detailed and highly accurate but covered only approximately $5-10 \%$ of vessels operating in the TPO. The environmental factors in the study were significant in the selected GAMs, but the $1^{\circ}$ spatial grid data had higher cumulative deviances; the observed catch rates were highly correlated with the predicted relative catch rates. However, the O-data map showed the high-quality spatial resolutions of the predicted relative catch rates in the close-view maps. Thus, these results suggest that models of catch rates of the $1^{\circ}$ spatial grid data that incorporate relevant environmental variables can be used to infer possible responses in the distribution of highly migratory species. Furthermore, the O-data can be used to detect subtle changes in the target fishing grounds.

\section{Conclusions}

Understanding the effects of environmental conditions on fish catch rates is an essential step toward ecosystem-based management of fisheries, which is increasingly becoming a standard approach in management policy $[39,40]$. For example, the impact of climate variability leads to changes in the fishing location, which increases the cost associated with the movement of fishing vessels and the oil. Some oceanic factors derived from the model, such as atmosphere-ocean general circulation models (which are appropriate for simulating climatic scenarios) and those developed in this paper, can be used for predicting the future distribution and abundance of fish species [23,41]. The predicted fish habitat variability can help to maintain constant fish catch rates despite climate-driven interannual variability and help to prevent overfishing in periods of fish abundance. Thus, the results of this study suggest that models of catch rates of the $1^{\circ}$ spatial grid data that incorporate relevant environmental variables can be used to infer possible responses in the distribution of highly migratory species, and the O-data can be used to detect subtle changes in the target fishing grounds.

The processes associated with environmental variations that influence the spatial pattern of yellowfin tuna remain unclear in this study. Dissolved oxygen and feeding behavior are critical constraints considering the vertical and horizontal distributions of yellowfin tuna. Furthermore, studies on the habitat of each cohort of yellowfin tuna related to environment variability are unexplored. Large-scale movements and coarse-scale distributions can be considered the composite results of many fine-scale behavioral "decisions," in which fish cohorts react to ambient conditions with respect to 
their environmental and physiological requirements [42,43]. Future studies must investigate the distributions of yellowfin tuna cohorts by simulating animal responses to the spatial heterogeneity of biotic and abiotic conditions in a dynamic marine landscape.

Acknowledgments: This study was financially supported by the Council of Agriculture (105AS-11.1.5-FA-F1 and 105AS-11.1.5-FA-F1(5)) and the National Science Council (104-2611-M-019-012 and 105-2611-M-019-015). The authors are grateful to the Overseas Fisheries Development Council of Taiwan for providing data from the Taiwanese longline fishery industry. The altimeter products were produced by the CLS Space Oceanography Division as part of the Environment and Climate EU ENACT project (EVK2-CT2001-00117) and with support from CNES.

Author Contributions: Kuo-Wei Lan led the study design and wrote the article. Ming-An Lee and Nan-Jay Su contributed materials of fishery data and analysis models. Teruhisa Shimada and Yi Chang wrote the code for downloading and processing the remote-sensing environmental data.

Conflicts of Interest: The authors declare no conflict of interest.

\section{References}

1. Schaefer, K.M.; Fuller, D.W.; Block, B.A. Movements, behavior, and habitat utilization of yellowfin tuna (Thunnus albacares) in the northeastern Pacific Ocean, ascertained through archival tag data. Mar. Biol. 2007, 152, 503-525. [CrossRef]

2. Heithaus, M.R.; Frid, A.; Wirsing, A.J.; Worm, B. Predicting ecological consequences of marine top predator declines. Trends Ecol. Evol. 2008, 23, 202-210. [CrossRef] [PubMed]

3. Kitchell, J.F.; Essington, T.E.; Boggs, C.H.; Schindler, D.E.; Walters, C.J. The role of sharks and longline fisheries in a pelagic ecosystem of the central Pacific. Ecosystems 2002, 5, 202-216. [CrossRef]

4. Ward, P.; Myers, R.A. Shifts in open-ocean fish communities coinciding with the commencement of commercial fishing. Ecology 2005, 86, 835-847. [CrossRef]

5. Polovina, A.J.J.; Woodworth-Jefcoats, P.A. Fishery-Induced Changes in the Subtropical Pacific Pelagic Ecosystem Size Structure: Observations and Theory. PLoS ONE 2013, 8, e62341. [CrossRef] [PubMed]

6. Dickey, T.D. Emerging ocean observations for interdisciplinary data assimilation systems. J. Mar. Syst. 2003, 40, 5-48. [CrossRef]

7. Alabia, I.D.; Saitoh, S.I.; Igarashi, H.; Ishikawa, Y.; Usui, N.; Kamachi, M.; Seito, M. Ensemble squid habitat model using three-dimensional ocean data. ICES J. Mar. Sci. J. Conseil 2016, 73, 1863-1874. [CrossRef]

8. Damalas, D.; Megalofonou, P. Discovering where bluefin tuna, Thunnus thynnus (Linnaeus, 1785), might go: Using environmental and fishery data to map potential tuna habitat in the Eastern Mediterranean Sea. Sci. Mar. 2012, 76, 691-704.

9. Lan, K.W.; Evans, K.; Lee, M.A. Effects of climate variability on the distribution and fishing conditions of yellowfin tuna (Thunnus albacares) in the western Indian Ocean. Clim. Chang. 2013, 119, 63-77. [CrossRef]

10. Nieto, K.; Xu, Y.; Teo, S.L.H.; McClatchie, S.; Holmes, J. How important are coastal fronts to albacore tuna (Thunnus alalunga) habitat in the Northeast Pacific Ocean? Prog. Oceanogr. 2017, 150, 62-71. [CrossRef]

11. Langley, A.; Briand, K.; Kirby, D.S.; Murtugudde, R. Influence of oceanographic variability on recruitment of yellowfin tuna (Thunnus albacares) in the western and central Pacific Ocean. Can. J. Fish. Aquat. Sci. 2009, 66, 1462-1477.

12. Sund, P.N.; Blackburn, M.; Willians, F. Tunas and their environment in the Pacific Ocean: A review. Oceanogr. Mar. Biol. Ann. Rev. 1981, 19, 443-512.

13. Dell, J.; Wilcox, C.; Hobday, A.J. Estimation of yellowfin tuna (Thunnus albacares) habitat in waters adjacent to Australia's East Coast: Making the most of commercial catch data. Fish. Oceanogr. 2011, 20, 383-396. [CrossRef]

14. Yen, K.W.; Lu, H.J.; Chang, Y.; Lee, M.A. Using remote-sensing data to detect habitat suitability for yellowfin tuna in the Western and Central Pacific Ocean. Int. J. Remote Sens. 2012, 33, 7507-7522. [CrossRef]

15. Lan, K.W.; Nishida, T.; Lee, M.A.; Lu, H.J.; Huang, H.W.; Chang, S.K.; Lan, Y.C. Influence of the marine environment variability of the yellowfin tuna (Thunnus albacares) catch rate by the Taiwanese longline fishery in the Arabian Sea, with special reference to the high catch in 2004. J. Mar. Sci. Technol. 2012, 20, 514-524.

16. Polovina, J.J.; Howell, E.A. Ecosystem indicators derived from satellite remotely sensed oeeanographie data for the North Pacific. ICES J. Mar. Sci. 2005, 62, 319-327. [CrossRef] 
17. Lan, K.W.; Lee, M.A.; Lu, H.J.; Shieh, W.J.; Lin, W.K.; Kao, S.C. Ocean variations associated with fishing conditions of yellowfin tuna (Thunnus albacares) in the equatorial Atlantic Ocean. ICES J. Mar. Sci. 2011, 68, 1063-1071. [CrossRef]

18. Ishikawa, Y.; Awaji, T.; Toyoda, T.; In, T.; Nishina, K.; Nakayama, T.; Shima, S.; Masuda, S. High-resolution synthetic monitoring by a 4-dimensional variational data assimilation system in the northwestern North Pacific. J. Mar. Syst. 2009, 78, 237-248. [CrossRef]

19. Nakada, S.; Hirose, N.; Senjyu, T.; Fukudome, K.I.; Tsuji, T.; Okei, N. Operational ocean prediction experiments for smart coastal fishing. Prog. Oceanogr. 2014, 121, 125-140. [CrossRef]

20. Chang, S.K.; Hoyle, S.; Liu, H.I. Catch rate standardization for yellowfin tuna (Thunnus albacares) in Taiwan's distant-water longline fishery in the Western and Central Pacific Ocean, with consideration of target change. Fish. Res. 2011, 107, 210-220. [CrossRef]

21. Su, N.J.; Sun, C.L.; Punt, A.E.; Yeh, S.Z.; DiNardo, G. Environmental influences on seasonal movement patterns and regional fidelity of striped marlin Kajikia audax in the Pacific Ocean. Fish. Res. 2015, 166, 59-66. [CrossRef]

22. Lehodey, P. Climate and fisheries: An insight from the Pacific Ocean. In Ecological Effects of Climate Variations in the North Atlantic; Stenseth, N.C., Ottersen, G., Hurrel, J., Belgrano, A., Eds.; Oxford University Press: Oxford, UK, 2004; pp. 137-146.

23. Lehodey, P.; Hampton, J.; Brill, R.W.; Nicol, S.; Senina, I.; Calmettes, B.; Pørtner, H.O.; Bopp, L.; Ilyina, T.; Bell, J.D.; et al. Vulnerability of Tropical Pacific Fisheries and Aquaculture to Climate Change; Bell, J.D., Johnson, J.E., Hobday, A.J., Eds.; Secretariat of the Pacific Community: Noumea, New Caledonia, 2011; pp. 433-492.

24. Maunder, M.N.; Punt, A.E. Standardizing catch and effort data: A review of recent approaches. Fish. Res. 2004, 70, 141-159. [CrossRef]

25. Mugo, R.; Saitoh, S.I.; Nihira, A.; Kuroyama, T. Habitat characteristics of skipjack tuna (Katsuwonus pelamis) in the western North Pacific: A remote sensing perspective. Fish. Oceanogr. 2015, 19, 382-396. [CrossRef]

26. Wood, S.M. Generalized Additive Models, an Introduction with R; Chapman and Hall: London, UK, 2006 ; p. 392.

27. Pearman, P.B.; Guisan, A.; Broennimann, O.; Randin, C.F. Niche dynamics in space and time. Trends Ecol. Evol. 2008, 23, 149-158. [CrossRef] [PubMed]

28. Vincent, D.G. The South Pacific Convergence Zone (SPCZ): A review. Mon. Weather Rev. 1994, 122, $1949-1970$. [CrossRef]

29. Rayner, N.A.; Brohan, P.; Parker, D.E.; Folland, C.K.; Hardwick, J.; Kennedy, J.; Vanicek, M.; Ansell, T.; Tett, S.F.; Kent, E.C. Improved analyses of changes and uncertainties in marine temperature measured in situ since the mid-nineteenth century: The HadSST2 dataset. J. Clim. 2005, 19, 446-469. [CrossRef]

30. Prince, E.D.; Goodyear, C.P. Hypoxia-based habitat compression of tropical pelagic fishes. Fish. Oceanogr. 2006, 15, 451-464. [CrossRef]

31. Yen, K.W.; Lu, H.J. Spatial-temporal variations in primary productivity and population dynamics of skipjack tuna Katsuwonus pelamis in the western and central Pacific Ocean. Fish. Sci. 2016, 82, 563-571. [CrossRef]

32. Menard, F.; Marsac, F.; Bellier, E.; Cazelles, B. Climatic Oscillations and tuna catch rates in the Indian Ocean: A wavelet approach of time series analysis. Fish. Oceanogr. 2007, 16, 95-104. [CrossRef]

33. Rebert, J.P.; Donguy, J.R.; Eldin, G.; Wyrtki, K. Relations between sea level, thermocline depth, heat content, and dynamic height in the tropical Pacific Ocean. J. Geophys. Res. Oceans 1985, 90, 11719-11725. [CrossRef]

34. Le Traon, P.Y.; Dibarboure, G. Mesoscale mapping capabilities from multiple altimeter missions. J. Atmos. Ocean. Technol. 1999, 16, 1208-1223. [CrossRef]

35. Ducet, N.; Le Traon, P.Y.; Reverdin, G. Global high-resolution mapping of ocean circulation from the combination of T/P and ERS-1/2. J. Geophys. Res. 2000, 105, 19477-19498. [CrossRef]

36. Sournia, A. Pelagic biogeography and fronts. Prog. Oceanogr. 1994, 34, 109-120. [CrossRef]

37. Bertrand, A.; Josse, E.; Bach, P.; Gros, P.; Dagorn, L. Hydrological and trophic characteristics of tuna habitat: Consequences on tuna distribution and longline catchability. Can. J. Fish. Aquat. Sci. 2002, 59, 1002-1013. [CrossRef]

38. Lee, Y.C.; Liu, H.C. The tuna statistics procedures of Taiwan longline and gillnet Fisheries in the Indian Ocean. IPTP Collectiv. Vol. 1996, 9, 368-369.

39. Austin, M. Species distribution models and ecological theory: A critical assessment and some possible new approaches. Ecol. Model. 2007, 200, 1-19. [CrossRef] 
40. Zhang, C.I.; Hollowed, A.B.; Lee, J.B.; Kim, D.H. An IFRAME approach for assessing impacts of climate change on fisheries. ICES J. Mar. Sci. 2011, 68, 1318-1328. [CrossRef]

41. Cheung, W.W.L.; Dunne, J.; Sarmiento, J.L.; Pauly, D. Integrating ecophysiology and plankton dynamics into projected maximum fisheries catch potential under climate change in the Northeast Atlantic. ICES J. Mar. Sci. 2011, 68, 1008-1018. [CrossRef]

42. Flierl, G.; Grünbaum, D.; Levin, S.A.; Olson, D. From individuals to aggregations: The interplay between behavior and physics. J. Theor. Biol. 1999, 196, 397-454. [CrossRef] [PubMed]

43. Humston, R.; Olson, D.B.; Ault, J.S. Behavioral assumptions in models of fish movement and their influence on population dynamics. Trans. Am. Fish. Soc. 2004, 133, 1304-1328. [CrossRef]

(C) 2017 by the authors. Licensee MDPI, Basel, Switzerland. This article is an open access article distributed under the terms and conditions of the Creative Commons Attribution (CC BY) license (http:/ / creativecommons.org/licenses/by/4.0/). 